\title{
Predatory flagellates - the new recently discovered deep branches of the eukaryotic tree and their evolutionary and ecological significance
}

\author{
Denis V. Tikhonenkov \\ Papanin Institute for Biology of Inland Waters, Russian Academy of Sciences, Borok, \\ 152742, Russia
}

| Submitted March 20, 2020 | Accepted April 6, 2020 |

\begin{abstract}
Summary
Predatory protists are poorly studied, although they are often representing important deep-branching evolutionary lineages and new eukaryotic supergroups. This short review/opinion paper is inspired by the recent discoveries of various predatory flagellates, which form sister groups of the giant eukaryotic clusters on phylogenetic trees, and illustrate an ancestral state of one or another supergroup of eukaryotes. Here we discuss their evolutionary and ecological relevance and show that the study of such protists may be essential in addressing previously puzzling evolutionary problems, such as the origin of multicellular animals, the plastid spread trajectory, origins of photosynthesis and parasitism, evolution of mitochondrial genomes.
\end{abstract}

Key words: evolution of eukaryotes, heterotrophic flagellates, mitochondrial genome, origin of animals, photosynthesis, predatory protists, tree of life

\section{Predatory flagellates and diversity of eu- karyotes}

The well-studied multicellular animals, plants and fungi immediately come to mind when we hear the term "eukaryotes". However, these groups of organisms represent a minority in the real diversity of evolutionary lineages of eukaryotes. Most eukaryotes are unicellular and only unicellular forms existed during the most of eukaryotic evolution (O’Malley et al., 2012; Betts et al., 2018; Keeling, 2019; Keeling and Burki, 2019).

An increasing number of metagenomic studies devoted to total DNA sequencing of natural samples revealed a huge number of sequences not belonging to known species, thus illustrating the high potential of the hidden diversity of protists (Moon-van der Staay et al., 2000; López-García et al., 2001; Edgcomb et al., 2002; Massana et al., 2004; Richards and Bass, 2005; Tarbe et al., 2011; de Vargas et al., 2015). In particular, several prevailing and very abundant ribogroups such as MALV, MAST, MAOP, MAFO (marine alveolates, stramenopiles, opisthokonts and fonticulids, respectively), deep-sea pelagic diplonemids (DSPD) or eupelagonemids (Guillou et al., 2008; Massana and Pedrys-Aliy, 2008; del Campo and Ruiz-Trillo, 2013; del Campo et al., 2015; Okamoto et al., 2019) as well as myriad of small new subgroups phylogenetically associated with almost all large eukaryotic taxa were identified in natural ecosystems (del Campo et al., 2016; Keeling and del Campo, 2017). Most

doi:10.21685/1680-0826-2020-14-1-2 
likely, the discoveries of new ribogroups of protists will continue with the metagenomic sequencing of almost any natural samples for many more years.

However, it is not always possible to evaluate the diversity of protists reliably. Even metagenomic approaches often do not work, especially those utilizing universal primers for amplification of ribosomal genes in total DNA from a sample. This is especially true for predatory (eukaryotrophic) protists that frequently do not reach high numbers in natural communities. Keeling and Burki (2019) provided a catchy example of such situation: "Imagine for a moment that you are visiting the Earth from another planet to investigate biodiversity, and randomly select 1000 animals from a patch of the Serengeti. You may come to the correct conclusion that wildebeest and gazelles are common, but you may not realize that lions and leopards even exist, or you may write them off as insignificant 'rare biosphere' taxa. But, of course, they play a crucial role in the ecosystem and represent a significant branch in the tree of animals".

Therefore, researchers rarely observe predatory flagellates microscopically and in the environmental sequencing surveys. Most likely, this is because such protists occupy the upper levels of microbial food webs and never reach high abundances in the communities, although they are able to play a critical role in the matter and energy flows in the ecosystems (Tikhonenkov et al., 2014). At the same time, predatory flagellates may constitute a significant part of eukaryotes' taxonomic diversity (especially considering the macrotaxa), including groups so far unknown to researchers.

\section{Ecological importance of predatory flagel- lates}

Actualization of ideas on biodiversity and ecology is currently impossible without considering unicellular heterotrophic protists. Heterotrophic flagellates are the least studied component of water and soil biocenoses, although the enormous role of these protozoans in their functioning has long been understood. These tiny organisms are a compulsory link in "microbial loops" that provide effective pathways for the transformation of matter and energy in aquatic ecosystems (Azam et al., 1983; Fenchel et al., 1995; Domaizon et al., 2003). While being characterized by heterotrophic nutrition, these tiny unicellular eukaryotes vary significantly in trophic preferences (bacteriotrophs, (pico) algophages, detritophages, osmotrophs, eukaryotrophs, euryphages, etc.), feeding strategies, sizes, and many other ecological characteristics (Arndt et al., 2000; Boenigk and Arndt, 2002). Different species, even within similar taxonomic groups, can often differ in ecophysiology: polymorphism of life cycles, degree of tolerance to physical and chemical factors, different cellular metabolism, mode of locomotion, nutritional strategies and methods of food capture and absorption, bioenergetic growth balance (Fenchel, 1987; Sleigh, 2000). Flagellates are an extremely diverse "hodgepodge" of the smallest and most mobile eukaryotes with significantly different evolutionary origin, metabolism and ecology. They possess the full range of trophic and life strategies seen in eukaryotes, albeit on a microscopic scale. Assessment of their diversity, features of their biology and ecology are extremely important for a deeper understanding of the role of these organisms in the functional organization of aquatic ecosystems.

Predatory eukaryotrophic flagellates are the worst studied in this regard. Their contribution to the trophic structure and functioning of aquatic ecosystems is not fully understood. Rapid feeding behavior of Colponema, Acavomonas, Ancoracysta, Rhodelphis and other predatory flagellates associated with fast reproduction was observed (Tikhonenkov et al., 2014; Janouškovec et al., 2017; Gawryluk et al., 2019). Many of them are obligate eukaryovores which actively feed on other flagellates (e.g. ubiquitous heterotrophic chrysophytes and bodonids), and could not be sustained on bacteria alone. This points to a potentially important ecological role of predatory flagellates as regulators of small flagellate abundance, which are themselves often major grazers of bacteria (Tikhonenkov et al., 2014). Study of these protists is therefore critical for understanding the functioning of microbial food webs.

\section{Tree of life and evolutionary importance of predatory flagellates}

The division of eukaryotes into animal, plant, fungi and protist kingdoms was commonly accepted only 30 years ago. However, it turned out that animals, plants and fungi as descendants of some unicellular ancestors possess closer relatives within protists and therefore represent only small branchlets on the branched phylogenetic tree of unicellular organisms.

At present, it is well known that protists represent many phylogenetic lineages (Fig. 1), which are 


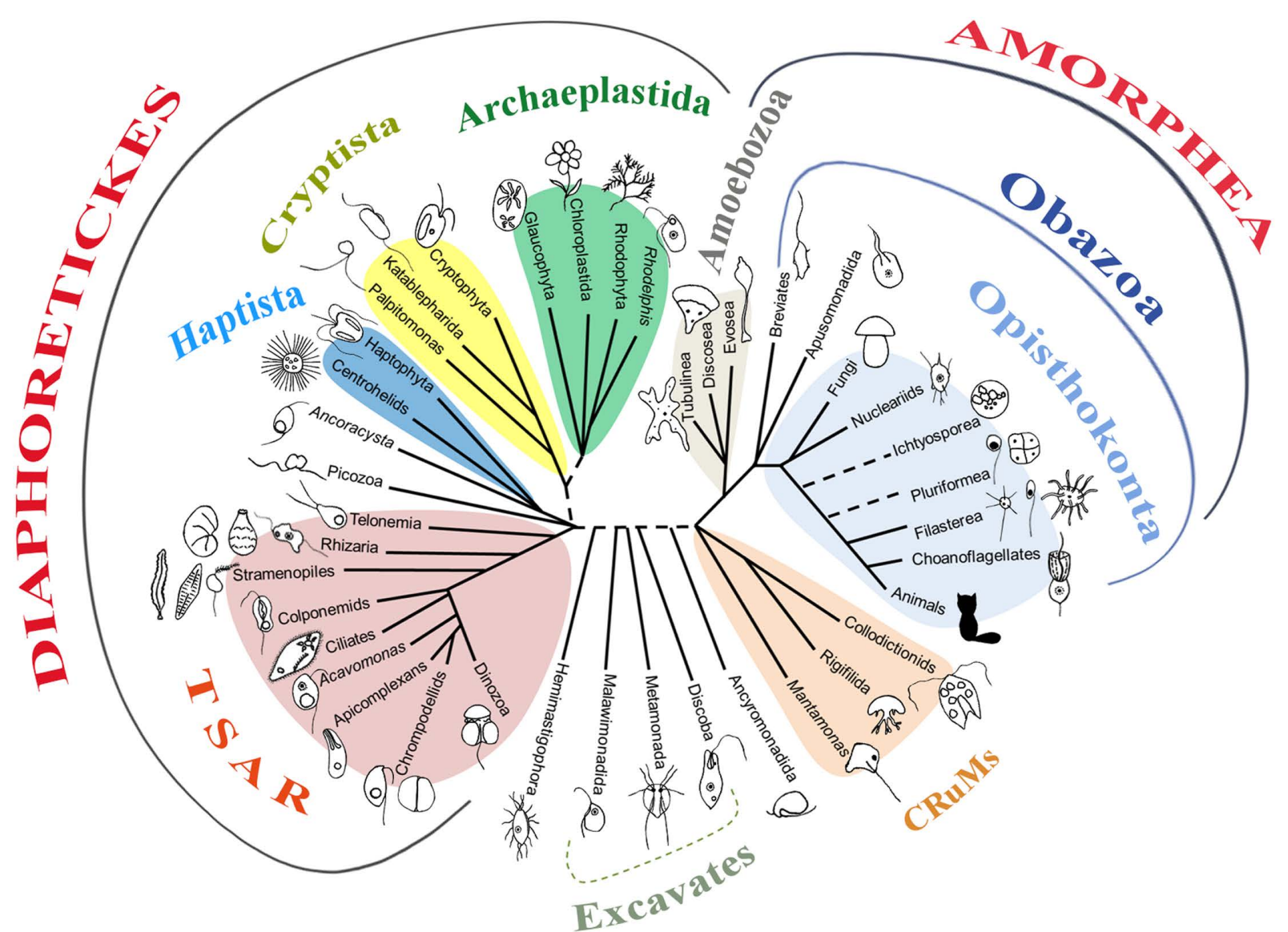

Fig. 1. The eukaryotic tree of life according current phylogenomic studies and morphological and cell-biology data. The well-established supergroups are boxed in color. Unresolved places of the tree are indicated by dashed lines.

equivalent to traditional kingdoms, and contain a huge number of species that possess ancestral cellular and genomic characteristics in relation to their multicellular relatives (Keeling and Burki, 2019).

The development of ideas on the eukaryotic tree of life is largely due to multigene phylogeny, often based on data from transcriptomic and genomic projects. This is largely due to the greater availability of high-throughput sequencing methods on Illumina and PacBio platforms, as well as nanopore sequencing. As a result, the outlines of the general eukaryotic macrosystem, the latest version of which was published in 2019 (Adl et al., 2019), are currently appearing in the works of various researchers. Two giant eukaryotic superclusters, Amorphea and Diaphoretickes, include supertaxa Obazoa, Amoebozoa, CRuMs, Archaeplastida, SAR, Haptista, Cryptista (Fig. 1). A large number of incertae sedis eukaryotic groups are also known, the largest of them being excavates (Excavata: heterolobose amoeba, acrasids, trypanosomes, euglenids, trichomonads, Giardia, etc.).

The main problems in terms of resolving family ties, the origin and evolution of macrotaxa are associated with the lack of data on organisms placed at the base of the phylogenetic lineages of eukaryotes. Heterotrophic flagellates - generally the oldest and most simply organized eukaryotes, are the most promising candidates, the study of which can help solve these problems.

At present, the number of heterotrophic protists with available molecular data (mainly on ribosomal genes) is significantly increasing. Many new protists (new taxa sometimes) are discovered or rediscovered, especially in poorly studied biotopes: soils, bottom sediments, and extreme habitats. Thus, the recent discovery and phylogenomic study of representatives of a poorly known group of flagellates Hemimastigophora has led to the disclosure of a new high-ranking phylogenetic lineage of eukaryotes. It turned out that the Hemimastigo- 


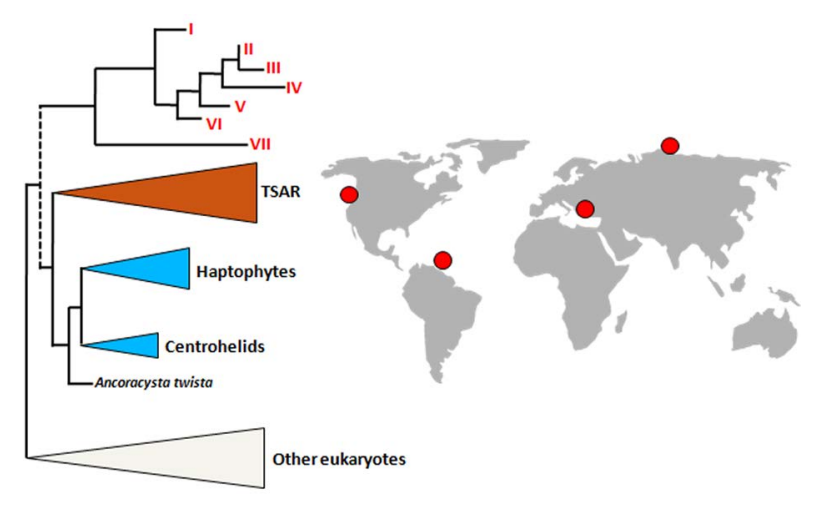

Fig. 2. Scheme of the putative evolutionary position (SSU RNA gene, maximum likelihood phylogeny) and geographic distribution (red circles) of the probable new lineage of predatory flagellates represented by seven clones (I-VII).

phora is most probably sister to the huge supercluster Diaphoretickes, which includes almost all photosynthetic eukaryotes (Lax et al., 2018). It is obvious that this is only the tip of the iceberg of unexplored new evolutionary lineages of protists.

We have discovered several representatives of the novel clade, which probably does not belong to any known group of eukaryotes according to small subunit ribosomal RNA gene phylogeny (Fig. 2). These organisms may belong to another previously unknown supergroup of eukaryotes although multigene phylogenomic analyses are needed. These protists were isolated from geographically remote marine biotopes of different types including coral reefs in Curacao, bottom sediments of Crimea, Arctic Ocean plankton and North-East Pacific Ocean. They are predatory flagellates resembling Ancoracysta morphotype, but become much smaller, about $3 \mu \mathrm{m}$ long if they starve in the absence of eukaryotic prey, possibly representing the understudied picofraction of eukaryotes in the ocean.

Our knowledge on predatory heterotrophic flagellates is scarce presently, although phylogenetic data on them are extremely valuable for reconstruction of the universal tree of life. Scarcity of data on such organisms not only maintains a gap in our understanding of microbial diversity, but also affects our interpretation of their better-studied relatives. The basal or intermediate evolutionary positions occupied by these organisms make them particularly important for elucidating the origin and evolution of some major and well-studied lineages and groups (Tikhonenkov et al., 2014) as well as for addressing key questions of general interest.

\section{ORIGIN OF PHOTOSYNTHETIC EUKARYOTES}

The incorporation of photosynthetic cyanobacterium into the phagotrophic protozoa cell led to the emergence and further radiation of Archaeplastida, the eukaryotic supergroup, united by the common origin of plastids by primary endosymbiosis. Archaeplastids include Viridiplantae (green algae and land plants), glaucophytes (Glaucophyta) and red algae (Rhodophyta) (Adl et al., 2019).

Recent discovery of the predatory flagellates Rhodelphis (Fig. 3, A), assigned to Rhodelphidia, a new taxonomic phylum of eukaryotes (Gawryluk et al., 2019), revealed that their representatives are the closest relatives of red algae, although being completely different in the way of life: they are nonphotosynthetic flagellate predators with gene-rich genomes. They have a relict primary plastid, which is involved only in haem biosynthesis. In all likelihood, this means that the common ancestors of red algae and green plants were unicellular predators that, even after the acquisition of chloroplasts, retained a mixotrophic type of nutrition for a long time (predation + photosynthesis). Rhodelphis flagellates are, in fact, unicellular predatory plants that have survived to this day. It is possible that the ancestral Archaeplastida could have resembled Rhodelphis cells morphologically. We can assume that predatory flagellates, such as Rhodelphis, capable of feeding on relatively large $(6-9 \mu \mathrm{m})$ prey, could absorb large cyanobacteria that became the primary plastids.

\section{ORIGIN OF MULTICELLULAR ANIMALS}

The origin of multicellular animals is one of the largest and yet unsolved evolutionary mysteries. The diversity and biology of known unicellular relatives of animals has strongly enhanced our understanding on the transition from unicellular organisms to the multicellular Metazoa (King et al., 2008; Suga and Ruiz-Trillo, 2013; Suga et al., 2013).

New species of predatory unicellular flagellates Syssomonas and Pigoraptor (Hehenberger et al., 2017; Tikhonenkov et al., 2020a), distant unicellular relatives of animals playing an important role in clarifying their origin, have recently been identified and investigated. These protists (Fig. 3, B, C) possess a complex life cycle, can form multicellular aggregations and have eukaryotrophic nutrition unusual for unicellular Holozoa. In addition, they have genes encoding cell signal and adhesion proteins, as well as genes of embryonic development of multi- 


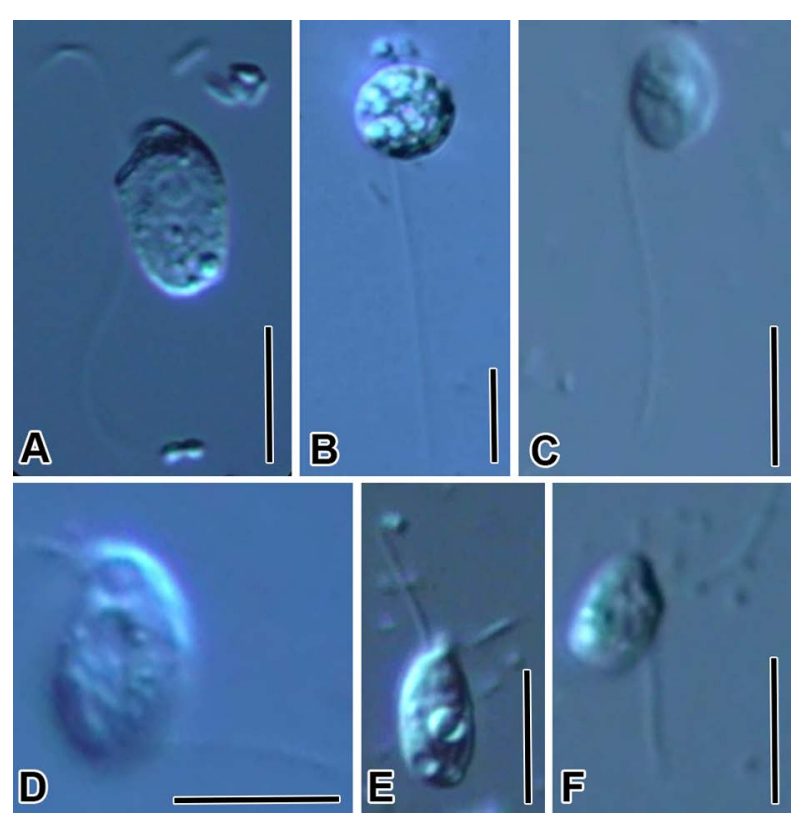

Fig. 3. External morphology of selected predatory flagellates. A - Rhodelphis limneticus, B - Syssomonas multiformis, C - Pigoraptor chileana, D - Colponema vietnamica, E - Telonema subtile, $\mathrm{F}-$ Ancoracysta twista. Scale bars $-10 \mu \mathrm{m}$.

cellular animals. It is assumed that the ancestor of multicellular animals formed various types of cells that could aggregate and had molecular mechanisms of cell differentiation and adhesion. At the same time, the nutrition of the Metazoa ancestor was more complex than previously thought, including not only bacteria, but also eukaryotic cells and organic structures. Apparently, its ability to consume large eukaryotic food objects could be a powerful trigger in the origin and formation of both the aggregated (formation of aggregations for co-nutrition) and clonal multicellularity (hypertrophic growth with subsequent palintomy) in Metazoa (Tikhonenkov et al., 2020a).

EVOLUTION OF ALVEOLATE PROTISTS AND ORIGIN OF MALARIA PARASITES

Alveolata is one of the largest and most diverse macrotaxa of eukaryotic microorganisms, including over 10,000 free-living and parasitic species. Two representatives of the predatory flagellate protists Colponema and Acavomonas, classified as two new taxonomic phyla of eukaryotes, Colponemidia and Acavomonidia within the supergroup Alveolata, have been identified and studied recently (Janouškovec et al., 2013; Tikhonenkov et al., 2014). The study of these protists and organisms related to them allowed reconstructing the early evolutionary events that gave rise to ciliates, malaria parasites and coral endosymbionts. It turned out that Acavomonas is the closest to the ancestors of apicomplexan parasites (malaria plasmodium and other sporozoans) and dinoflagellates (including zooxanthellae and toxic red tide microalgae). Flagellates Colponema (Fig. 3 , D) illustrate the ancestral form of all alveolate protists (apicomplexans, dinoflagellates and ciliates) (Tikhonenkov et al., 2020b). It has been established that the sister group to parasitic apicomplexans is the monophyletic clade, called "chrompodellids," including the predatory flagellates colpodellids and chromerid algae (Janouškovec et al., 2015). They revealed many protein-coding genes that were previously thought to be specific for parasitic apicomplexans, as well as those associated with apical complex organelles (rhoptry and microneme proteins, cytoskeletal SAS6L), which determine the possibility of a parasitic lifestyle. Thus, the origin and evolution of parasitic apicomplexans is associated with the loss and modification of genes and cell components that already existed in their free-living ancestors and their modern analogues - chromerid algae and predatory colpodellid flagellates (the phenomenon of pre-adaptation). The revealed family ties indicate a complex scenario for the acquisition, loss or modification of plastids and the evolution of parasitism in alveolates.

TREE OF EUKARYOTES AND EVOLUTION OF MITOCHONDRIAL GENOME

Recently, the eukaryote tree of life has been deeply remodeled, mainly due to the maturation of phylogenomics and the addition of numerous new 'kingdom-level' lineages of heterotrophic protists (Burki et al., 2020). For example, the systematic position of predatory flagellates telonemids (Telone$m a$, Fig. 3, E) has been established (Strassert et al., 2019). It turned out that telonemids are a deep phylogenetic lineage sister to the largest supergroup of eukaryotes SAR (Stramenopiles, Alveolata, Rhizaria). The SAR include heterokont algae (e.g., brown, diatom, golden, yellow-green algae), dinoflagellates, ciliates, apicomplexans, foraminiferans and radiolarians, oomycetes and many other microorganisms. Based on the topology of the phylogenomic tree, a new mega-group of eukaryotes was proposed, called TSAR (Telonemia + SAR). Since Telonemia occupy a key evolutionary position in exploring the origin of the SAR, further study will 
help shed light on how and due to what features/ factors the diversity of eukaryotes and their life strategies grew.

The predatory flagellate Ancoracysta twista (Fig. $3, \mathrm{~F})$, which does not belong to any of the known eukaryotic macrotaxa and represents a new deep phylogenetic lineage of the evolutionary tree, were revealed in samples from marine corals (Janouškovec et al., 2017). It carries extrusive organelles of an unknown type, called "ancoracysts". The mitochondrial genome of Ancoracysta is the most gene-rich known to science after the unrelated jakobids and Diphylleia. The analysis of the mitochondrial genes of Ancoracysta and other eukaryotes emphasizes that the gene-rich mitochondrial genomes do not indicate the position of the organism near the root of the eukaryotic tree. The evolutionary importance of parallel gene transfer from mitochondria to the nucleus in various organisms, as well as the exponential, lineage-specific reduction of mitochondrial genomes over time, was noted (Janouškovec et al., 2017).

\section{Conclusion}

Recent investigations and findings of new species, high-level taxa and even previously unknown phylogenetic lineages of eukaryotes demonstrate that heterotrophic (especially predatory) flagellates remain extremely poorly studied, although they often represent the most important deep-branching lineages of eukaryotes. They frequently form sister groups to giant eukaryotic clusters on phylogenetic trees, and illustrate an ancestral state of one or another supergroup of eukaryotes. Recent studies of predatory flagellates have provided new data essential for (a) revealing the early stages of evolution of Opisthokonta, Alveolata, and Archaeplastida supergroups; (b) leading to the revision of the eukaryotic tree and ideas on mitochondrial evolution and the root of the tree of all eukaryotic organisms; (c) demonstrating the ways of the emergence and development of unique cellular and genomic innovations that led to the formation of multicellularity, photosynthesis, and parasitism.

Further investigations of predatory flagellates are crucial for understanding the role of phagotrophy in the origin of symbiogenetic organelles - plastids and mitochondria; they will also help to clarify the evolution of major eukaryotic supergroups and resolve their relationships.

\section{Acknowledgements}

This work was supported by the Russian Foundation for Basic Research (grant no. 20-34-70049) and carried out within the framework of the project no. AAAA-A18-118012690098-5 of the Ministry of Education and Science of the Russian Federation.

\section{References}

Adl S.M., Bass D., Lane C.E., Lukeš J., Schoch C.L., Smirnov A., Agatha S., Berney C., Brown M.W., Burki F., Cárdenas P., Čepička I., Chistyakova L., del Campo J., Dunthorn M., Edvardsen B., Eglit Y., Guillou L., Hampl V., Heiss A.A., Hoppenrath M., James T.Y., Karnkowska A., Karpov S., Kim E., Kolisko M., Kudryavtsev A., Lahr D.J.G., Lara E., Le Gall L., Lynn D.H., Mann D.G., Massana R., Mitchell E.A.D., Morrow C., Park J.S., Pawlowski J.W., Powell M.J., Richter D.J., Rueckert S., Shadwick L., Shimano S., Spiegel F.W., Torruella G., Youssef N., Zlatogursky V. and Zhang Q. 2019. Revisions to the classification, nomenclature, and diversity of eukaryotes. J. Eukaryot. Microbiol. 55, 4-119.

Arndt H., Dietrich D., Auer B., Cleven E.J., Gräfenhan T., Weitere M. and Mylnikov A.P. 2000. Functional diversity of heterotrophic flagellates in aquatic ecosystems. In: The Flagellates: Unity, diversity and evolution. (Eds: Leadbeater B.S.C. and Green J.C.). Taylor and Francis, London, New York, pp. 240-268.

Azam F., Fenchel T., Field J.G., Gray J.S., Meyer-Reil L.A. and Thingstad F. 1983. The ecological role of water-column microbes in the sea. Mar. Ecol. Prog. 10, 257-263.

Betts H.C., Puttick M.N., Clark J.W., Williams T.A., Donoghue P.C.J. and Pisani D. 2018. Integrated genomic and fossil evidence illuminates life's early evolution and eukaryote origin. Nat. Ecol. Evol. 17, 1-10.

Boenigk J. and Arndt H. 2002. Bacterivory by heterotrophic flagellates: community structure and feeding strategies. Antonie Leeuwenhoek. 81, 465-480.

Burki F., Roger A.J., Brown M.W. and Simpson A.G.B. 2020. The new tree of eukaryotes. Trends Ecol. Evol. 35, 43-55.

de Vargas C., Audic S., Henry N., Decelle J., Mahé F., Logares R., Lara E., Berney C., Le Bescot N., Probert I., Carmichael M., Poulain J., Romac 
S., Colin S., Aury J.M., Bittner L., Chaffron S., Dunthorn M., Engelen S., Flegontova O., Guidi L., Horák A., Jaillon O., Lima-Mendez G., Lukeš J., Malviya S., Morard R., Mulot M., Scalco E., Siano R., Vincent F., Zingone A., Dimier C., Picheral M., Searson S., Kandels-Lewis S., Acinas S.G., Bork P., Bowler C., Gorsky G., Grimsley N., Hingamp P., Iudicone D., Not F., Ogata H., Pesant S., Raes J., Sieracki M.E., Speich S., Stemmann L., Sunagawa S., Weissenbach J., Wincker P. and Karsenti E. 2015. Ocean plankton. Eukaryotic plankton diversity in the sunlit ocean. Science. 348, 1261605.

del Campo J. and Ruiz-Trillo I. 2013. Environmental survey meta-analysis reveals hidden diversity among unicellular opisthokonts. Mol. Biol. Evol. 30, 802-805.

del Campo J., Mallo D., Massana R., de Vargas C., Richards T.A. and Ruiz-Trillo I. 2015. Diversity and distribution of unicellular opisthokonts along the European coast analyzed using high-throughput sequencing. Environ Microbiol. 17, 3195-3207.

del Campo J., Guillou L., Hehenberger E., Logares R., López-García P. and Massana R. 2016. Ecological and evolutionary significance of novel protist lineages. Eur. J. Protistol. 55, 4-11.

Domaizon I., Viboud S. and Fontvieille D. 2003. Taxon-specific and seasonal variations in flagellates grazing on heterotrophic bacteria in the oligotrophic Lake Annecy - importance of mixotrophy. FEMS Microbiol. Ecol. 46, 317-329.

Edgcomb V.P., Kysela D.T., Teske A., de Vera Gomez A. and Sogin M.L. 2002. Benthic eukaryotic diversity in the Guaymas Basin hydrothermal vent environment. Proc. Natl. Acad. Sci. U S A. 99, 7658-7662.

Fenchel T. 1987.The ecology of Protozoa. Madison, Springer-Verlag, Berlin.

Fenchel T., Bernard C., Esteban G., Finlay B.J., Hansen P.J. and Iversen N. 1995. Microbial diversity and activity in a Danish fjord with anoxic deep water. Ophelia. 43, 45-100.

Gawryluk R.M.R., Tikhonenkov D.V., Hehenberger E., Husnik F., Mylnikov A.P. and Keeling P.J. 2019. Non-photosynthetic predators are sister to red algae. Nature. 572, 240-243.

Guillou L., Viprey M., Chambouvet A., Welsh R.M., Kirkham A.R., Massana R., Scanlan D.J. and Worden A.Z. 2008. Widespread occurrence and genetic diversity of marine parasitoids belonging to Syndiniales (Alveolata). Environ. Microbiol. 10, 3349-3365.

Hehenberger E., Tikhonenkov D.V., Kolisko M., del Campo J., Esaulov A.S., Mylnikov A.P. and Keeling P.J. 2017. Novel freshwater predators reshape holozoan phylogeny and reveal the presence of a two-component signalling system in the ancestor of animals. Curr. Biol. 27, 2043-2050.

Janouškovec J., Tikhonenkov D., Mikhailov K.V., Simdyanov T.G., Aleoshin V.V., Mylnikov A.P. and Keeling P.J. 2013. Colponemids represent multiple ancient alveolate lineages. Curr. Biol. 25, 2546-2552.

Janouškovec J., Tikhonenkov D., Burki F., Howe A., Kolisko M., Mylnikov A.P. and Keeling P.J. 2015. Factors mediating plastid dependency and the origins of parasitism in apicomplexans and their close relatives. Proc. Natl. Acad. Sci. USA. 112, 10200-10207.

Janouškovec J., Tikhonenkov D., Burki F., Howe A.T., Rohwer F.L., Mylnikov A.P. and Keeling P.J. 2017. A new lineage of eukaryotes illuminates early mitochondrial genome reduction. Curr. Biol. 27, 3717-3724.

Keeling P.J. 2019. Combining morphology, behaviour, and genomics to understand the evolution and ecology of microbial eukaryotes. Philos. Trans. R. Soc. Lond. B. 374, 20190085.

Keeling P.J. and Burki F. 2019. Progress towards the Tree of Eukaryotes. Curr. Biol. 29, R808-R817.

Keeling P.J. and Campo J.D. 2017. Marine protists are not just big bacteria. Curr. Biol. 27, R541-R549.

King N., Westbrook M.J., Young S.L., Kuo A., Abedin M., Chapman J., Fairclough S., Hellsten U., Isogai Y., Letunic I., Marr M., Pincus D., Putnam N., Rokas A., Wright K.J., Zuzow R., Dirks W., Good M., Goodstein D., Lemons D., Li W., Lyons J.B., Morris A., Nichols S., Richter D.J., Salamov A., Sequencing J.G., Bork P., Lim W.A., Manning G., Miller W.T., McGinnis W., Shapiro H., Tjian R., Grigoriev I.V. and Rokhsar D. 2008. The genome of the choanoflagellate Monosiga brevicollis and the origin of metazoans. Nature. 451, 783-788.

Lax G., Eglit Y., Eme L., Bertrand E.M., Roger A.J. and Simpson A.G.B. 2018. Hemimastigophora is a novel supra-kingdom-level lineage of eukaryotes. Nature. 564, 410-414.

López-García P., Rodriguez Valera F., PedrysAliy C. and Moreira D. 2001. Unexpected diversity of small eukaryotes in deep-sea Antarctic plankton. Nature. 409, 603-607.

Massana R., Castresana J., Balague V., Guillou L., Romari K., Groisillier A., Valentin K. and Pedrys-Aliy C. 2004. Phylogenetic and ecological analysis of novel marine stramenopiles. Appl. Environ. Microbiol. 70, 3528-3534. 
Massana R. and Pedrys-Aliy C. 2008. Unveiling new microbial eukaryotes in the surface ocean. Curr. Opin. Microbiol. 11, 213-218.

Moon-van der Staay S.Y., Van der Staay G.W. M., Guillou L. and Vaulot D. 2000. Abundance and diversity of prymnesiophytes in the picoplankton community from the equatorial Pacific Ocean inferred from 18S rDNA sequences. Limnol. Oceanogr. $45,98-109$.

Okamoto N., Gawryluk R.M.R., del Campo J., Strassert J.F.H., Lukeš L., Richards T.A., Worden A.Z., Santoro A.E. and Keeling P.J. 2019. A revised taxonomy of diplonemids including the Eupelagonemidae n. fam. and a type species, Eupelagonema oceanic n. gen. et sp. J. Eukaryot. Microbiol. 66, 519-524.

O’Malley M.A., Simpson A.G.B. and Roger A.J. 2012. The other eukaryotes in light of evolutionary protistology. Biol. Philos. 28, 299-330.

Richards T.A. and Bass D. 2005. Molecular screening of free-living microbial eukaryotes: diversity and distribution using a meta-analysis. Curr. Opin. Microbiol. 8, 240-252.

Sleigh M.A. 2000. Trophic strategies. In: The flagellates: Unity, diversity and evolution. Taylor and Francis, London, New York, pp. 147-165.

Suga H. and Ruiz-Trillo I. 2013. Development of ichthyosporeans sheds light on the origin of metazoan multicellularity. Dev. Biol. 377, 284-292.

Suga H., Chen Z., de Mendoza A., Sebé-Pedrys A., Brown M.W., Kramer E., Carr M., Kerner P., Vervoort M., Sánchez-Pons N., Torruella G., Derelle R., Manning G., Lang B.F., Russ C., Haas
B.J., Roger A.J., Nusbaum C. and Ruiz-Trillo I. 2013. The Capsaspora genome reveals a complex unicellular prehistory of animals. Nat. Commun. 4, 2325.

Strassert J.F.H., Jamy M., Mylnikov A.P., Tikhonenkov D.V. and Burki F. 2019. New phylogenomic analysis of the enigmatic phylum Telonemia further resolves the eukaryote tree of life. Mol. Biol. Evol. 36,757-765.

Tarbe A., Stenuite S., Balague V., Sinyinza D., Descy J. and Massana R. 2011. Molecular characterisation of the small-eukaryote community in a tropical Great Lake (Lake Tanganyika, East Africa). Aquat. Microb. Ecol. 62, 177-190.

Tikhonenkov D.V., Janouškovec J., Mylnikov A.P., Mikhailov K.V., Simdyanov T.G., Aleoshin V.V. and Keeling P.J. 2014. Description of Colponema vietnamica sp.n. and Acavomonas peruviana $\mathrm{n}$. gen. n. sp., two new alveolate phyla (Colponemidia nom. nov. and Acavomonidia nom. nov.) and their contributions to reconstructing the ancestral state of alveolates and eukaryotes. PLoS ONE. 9, e95467.

Tikhonenkov D.V., Hehenberger E., Esaulov A.S., Belyakova O.I., Mazei Yu.A., Mylnikov A.P. and Keeling P.J. 2020a. Insights into the origin of metazoan multicellularity from predatory unicellular relatives of animals. BMC Biology. https:// doi.org/10.1186/s12915-020-0762-1.

Tikhonenkov D.V., Strassert J.F.S., Janouškovec J., Mylnikov A.P., Aleoshin V.V., Burki F. and Keeling P.J. 2020b. Predatory colponemids are the sister group to all other alveolates. bioRxiv. https:// doi.org/10.1101/2020.02.06.936658.

Address for correspondence: Denis Tikhonenkov. Papanin Institute for Biology of Inland Waters, Russian Academy of Sciences, Laboratory of Microbiology, Borok, 152742, Russia; e-mail: tikho-denis@yandex.ru . 